\title{
Study on High-Temperature Glass Lens Molding Process Using FEM Simulation
}

\author{
Zhang Xiaobing ${ }^{*}, 1,2$ and Yin Shaohui ${ }^{1}$ \\ ${ }^{I}$ College of Mechanical and Vehicle Engineering, Hunan University, Changsha, Hunan, P.R. China \\ ${ }^{2}$ Engineering Training Center, Hunan Institute of Engineer, Xiangtan, Hunan, P.R. China
}

\begin{abstract}
The glass molding process (GMP) can press glass perform into a shape of finished lens under high pressure and temperature conditions, and it is easy to achieve mass production. So, it has emerged as a promising alternative way to produce complex shapes lens. It is well known that viscoelastic is one important properties of glass at high temperature. In this study, A 4-pair generalized maxwell model was used to express viscoelastic of glass, and model parameters were obtained by fitting the relaxation curve obtained from experiment. The finite element models were established by MSC.MARC, the correctness of the FEM models and its used model parameters were verified by the cylindrical compression experiments. Finally, the simulations of glass lens forming stage were performed under different conditions. Stresses distribution were predicted by FEM, it was found that the maximum stress at the edge of lens, which make lens rupture easily at this zone. It was also discovered that the molding temperature is higher, the less stress, and the molding velocity is higher, the higher stress.
\end{abstract}

Keywords: FEM simulation, generalized Maxwell model, glass molding press (GMP), viscoelastic.

\section{INTRODUCTION}

Recently, aspherical lens are increasingly being used in many products, such as medical and scientific instruments $[1,2]$. Traditional ways to produce lens are not suitable mass production and dangerous to environment, an new manufacturing process is needed that can produce high precision aspherical lens. The glass molding press(GMP) has been a effective and economical alternative way to produce complex shapes lens gradually, more and more researchers pay attention to this technique [3,4]. The glass molding process can be classified into several different stages generally, as shown in Fig. (1). This process begins with a glass perform placed between molds, and subsequently the molds and glass perform are heated to a temperature between the transition and soften temperature of glass. Once the temperature of glass perform has reached a steady state, the upper and lower molds is closed with a specified speed. Finally, the formed lens are cooled to room temperature and then the finish lens are taken from the molds [5].

So far, there are still many problems that need to be solved during the process of GMP, such as mold life, optimization of process parameters and so on [6,7]. Finite element method (FEM) has been confirmed to be an effective and economic way to work out these problems.

The purpose of the present investigation is to built a validated FEM model to study the process parameters during lens molding process. In the paper, firstly, the cylindrical compression tests were done to attain model parameters.

*Address correspondence to this author at the College of Mechanical and Vehicle Engineering, Hunan University, Hunan, 410082, P.R. China;

Tel: (+86)13107123396; E-mail: zxbzxb12345@163.com
And then the FEM models of cylindrical compression using MSC. Marc were established based on attained model parameters. Meanwhile, the FEM models were verified by experiments. Finally, The numerical simulation of the aspherical lens forming process were simulated, the stress distribution in the lens and its influence factors were analyzed and discussed.

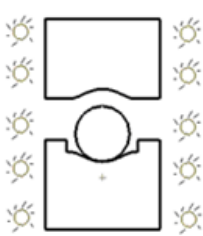

Mold and blank heating

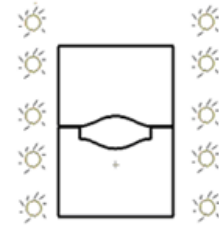

Lens forming and annealing

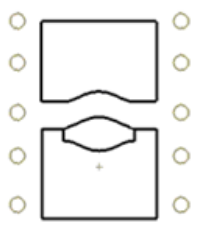

Cooling and releasing
Fig. (1). Schematic Diagram of A Glass Molding Process.

\section{MATERIAL PROPERITY AND ITS THEORET- ICAL MODELS}

As mentioned previously, the temperature of GMP is between the glass transition temperature and softening point temperature, at this temperature region, glass material expresses viscoelastic response which is a combination of viscous fluidity and elastic solidity [8]. Generally, the viscoelastic behavior can be represented by mechanical analogs consisting of springs and dashpots which help visualize and determine the relation between stress and strain in these materials. A schematic diagram of generalized Maxwell model is shown in Fig. (2), which can be used to model the stress relaxation behavior well. In Fig. (2), $G_{i}$ and 
$\eta_{i}$ are the shear modulus of the spring and the viscosity of the dashpot respectively, $n$ is the number of Maxwell elements. The constitutive equation of the stress relaxation can be written as follow:

$$
\sigma(t)=\int_{0}^{t} G(t-\tau) \frac{d \varepsilon}{d \tau} d \tau
$$

In the equation, $t$ is current time and $\tau$ represents past time. $G(t-\tau)$ is a varied value, which can be represented by a Prony series as in Eq. (2):

$$
G(t)=G_{0}\left(w_{\infty}+\sum_{i=1}^{n} w_{i} e^{-\frac{t}{t_{r i}}}\right)
$$

where $t_{r i}$ is relaxation time, $G_{0}$ is the instantaneous elastic shear modulus, and which is obtained from Eq. (3), $w_{i}$ is the weight factor for each Maxwell element, and which is in coincidence with Eq. (4)

$G_{0}=\frac{E_{0}}{2(1+v)}$

$E_{0}$ and $v$ are Young's modulus and Poisson's ratio in the Eq. (3), respectively.

$w_{\infty}+\sum_{i=1}^{n} w_{i}=1$

As we all known, The important characteristic of viscoelastic property is its strong correlation of temperature. This property can not be neglected during the building process of material models. The glass used in GMP usually can be characterized as thermo-rheologically simple material, so the effect of temperature can be described by correspondingly simple model. In this model, the temperature shift factor" function $(\mathrm{A}(\mathrm{T}))$ is used generally, which can be written as Eq. (5) as follow:

$\ln (A(T))=\frac{H}{R}\left(\frac{1}{T_{r e f}}-\frac{1}{T}\right)$

where $H$ and $R$ are the activation energy and gas constant respectively, $T_{r e f}$ is the reference temperature.

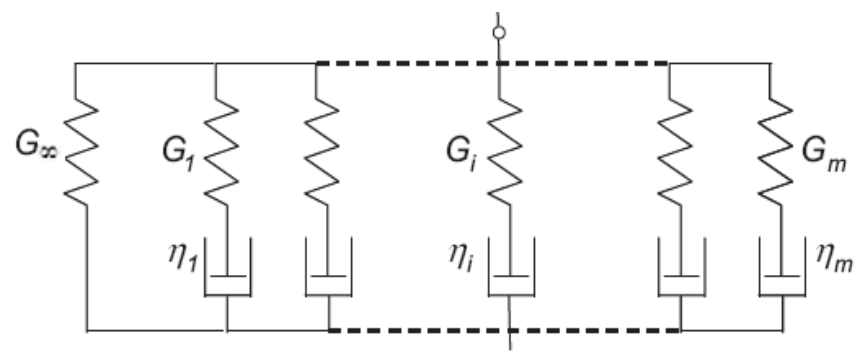

Fig. (2). Schematic diagram of viscoelastic model.

\section{EXPERIMENTAL MACHINE}

In order to investigate the glass molding press in the study, A compression molding machine was designed and produced. As shown in Fig. (3). One $10 \mathrm{KW}$ cylindrical furnace was used as a heat source for the machine, which can go up to a maximum temperature of $1500^{\circ} \mathrm{C}$ quickly. The instantaneous temperature in the furnace was controlled and monitored by a proportional-integral-derivative digital temperature controller. The continuous thrust for the machine is provided by a servo motor and an actuator with precise ball screw is drived by the servo motor. Through the ball screw the rotary motion of the motor is converted into linear motion. Speed, torque and the number of rotations of the motor controlled by programmable logic controller (PLC ) precisely are converted into straight line speed, thrust and position of the ball screw controlled respectively. In order to control and monitor instantaneous thrust, a load cell was installed on the lower mold. The PLC was connected to large touch screen through a serial port which permits to control and monitor load, speed and mold position during the tests.

(a)

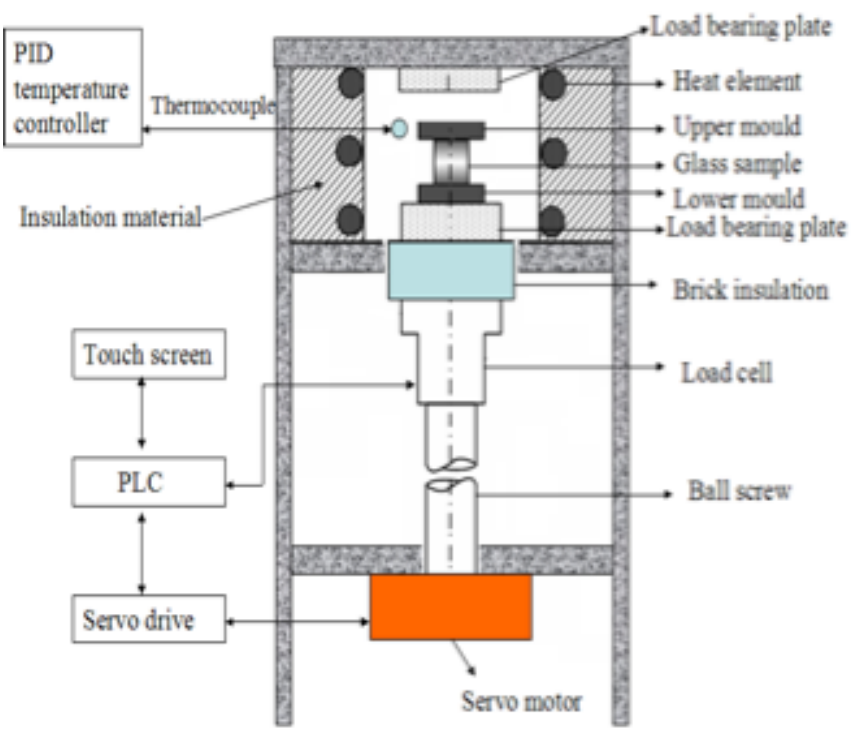

(b)

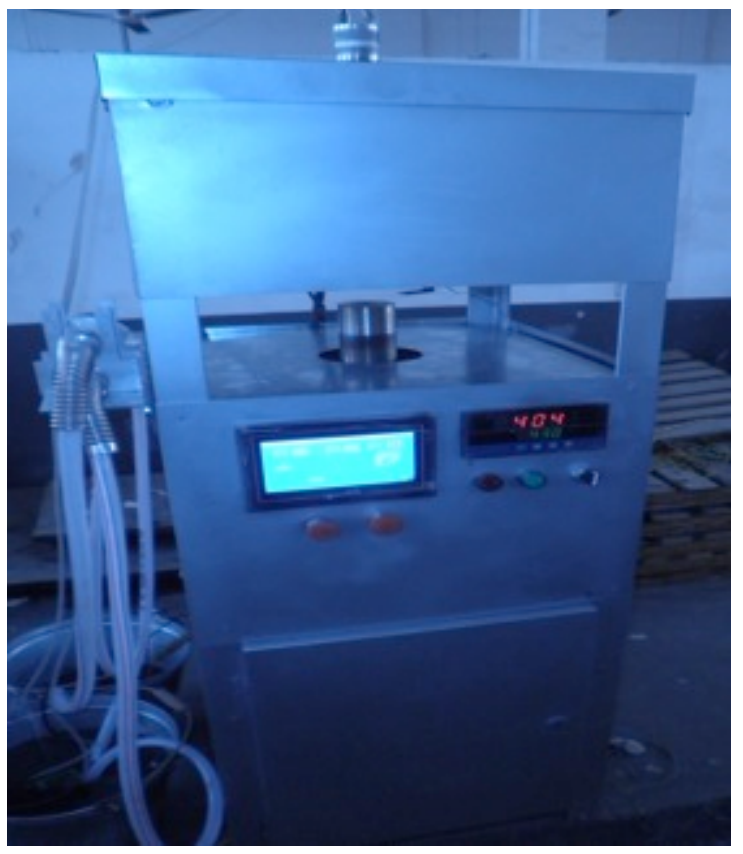

Fig. (3). Experimental setup for glass compression tests (a) schematic diagram (b) GMP setup. 


\section{RESULTS AND DISCUSSION}

\subsection{Material Model Used and its Verification}

In this research, The used glass is L-LAH84 with transition temperature about $527^{\circ} \mathrm{C}$, the elastic shear modulus and Poisson's ratio of L-LAH84 are $428 \mathrm{MPa}$ and 0.303 respectively. In order to attain the parameters of generalized Maxwell model for FEM simulation, the cylindrical sample with diameter and height of $10 \mathrm{~mm}$ was heated to $560^{\circ} \mathrm{C}$, and pressed at a velocity of $5 \mathrm{~mm} / \mathrm{min}$ until the load was up to the specified $400 \mathrm{~N}$. Then the mold was maintained still for load relaxation. The load relaxation curve at $560^{\circ} \mathrm{C}$ is shown in Fig. (4). The red continuous line is the curve fitted by a 4-pair general Maxwell model. Through fitting the detailed parameters of the model are attained, as shown in Table $\mathbf{1}$.

Table 1. Parameters of the general Maxwell model using in the simulation.

\begin{tabular}{|l|l|l|}
\hline 1 & 0.17163 & 0.80432 \\
\hline 2 & 0.36592 & 0.80448 \\
\hline 3 & 0.33023 & 0.43588 \\
\hline 4 & 0.10331 & 0.02292 \\
\hline
\end{tabular}

To verify that the proposed general Maxwell model with parameters listed in Table $\mathbf{1}$ is feasible for FE analysis under different temperature conditions, some comparisons between FE simulation results and experimental data were done. Numerical simulation was performed using the commercial non-linear finite element code MSC Marc. Only one half of the tooling and the sample are modeled because of the symmetry. Fig. (5) shows the two dimensional symmetric cylinder pressing model in the simulation. The upper and down molds were modeled as rigid bodies and the glass was modeled as a viscoelastic material with parameters given in Table 1. Axisymmetric quadrilateral element and adaptable element that is changed in the side of element number according to deformation of simulation model was used. Temperature-dependent properties of high temperature glass were accounted using a shift function $(\mathrm{A}(\mathrm{T}))$ which uses the user subroutine TRSFAC implemented in the simulation.

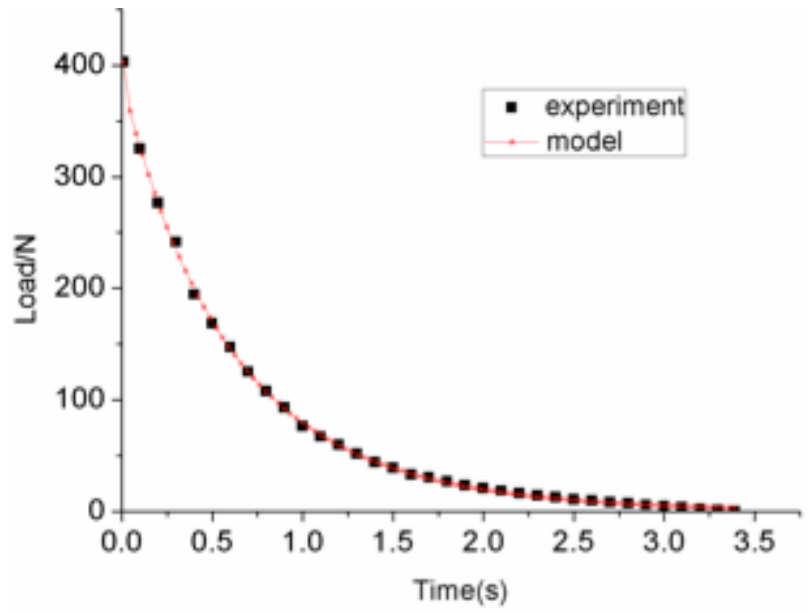

Fig. (4). Comparison of Load Relaxation between Experiment Data and Fitting Data Using a 4-pair General Maxwell Model at $560^{\circ} \mathrm{C}$.

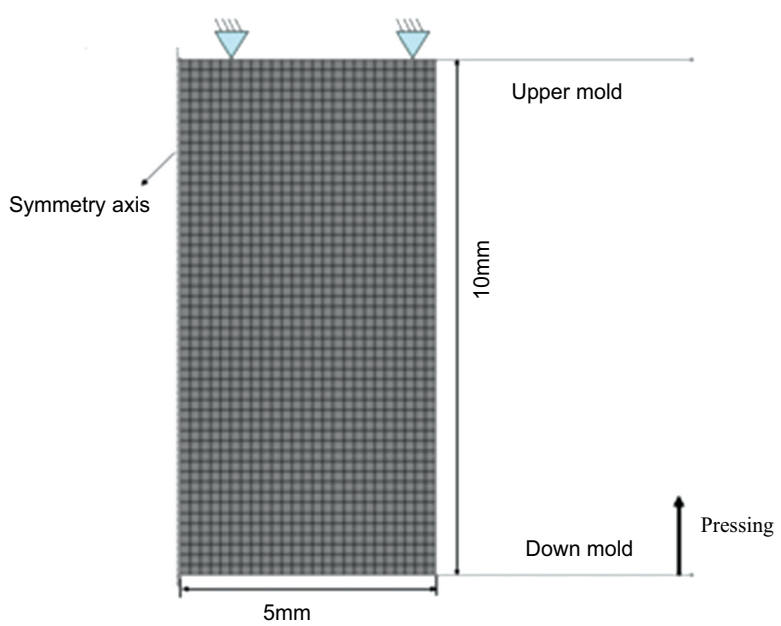

Fig. (5). Two Dimensional Symmetric Simulation Cylinder Pressing Model.

(a)

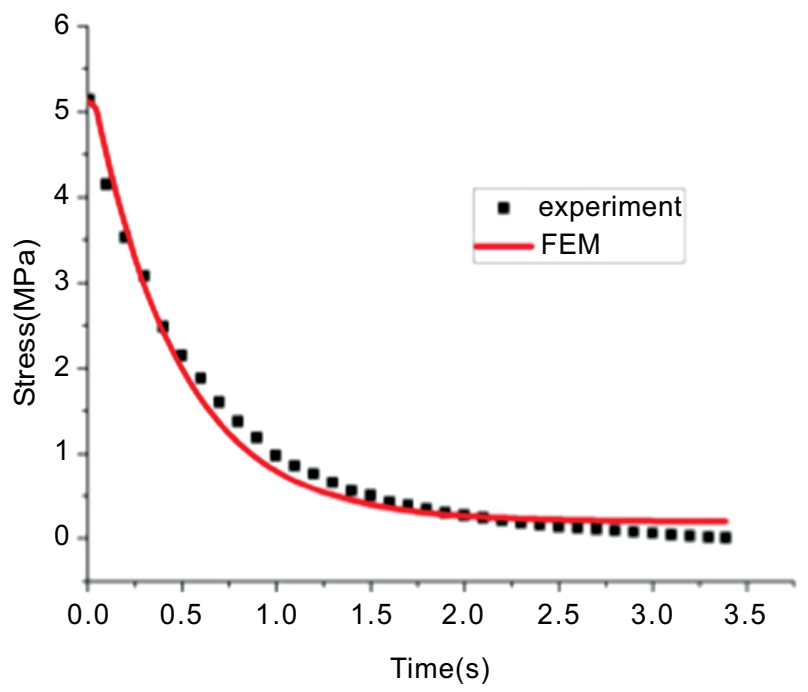

(b)

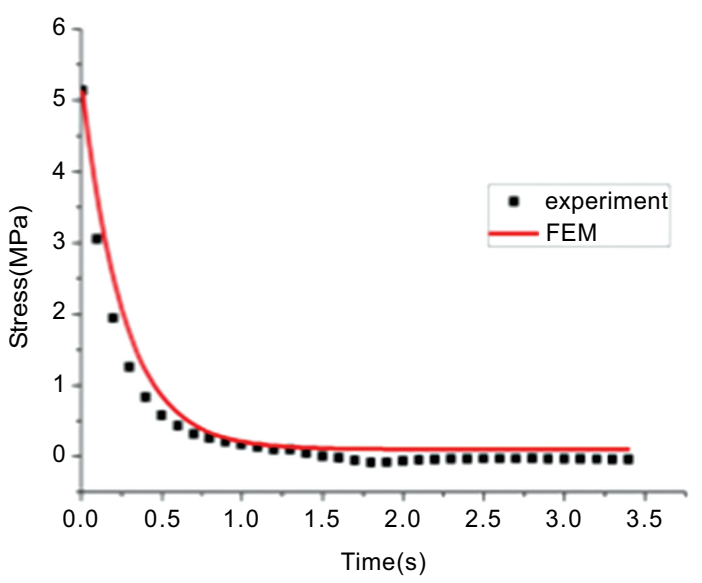

Fig. (6). Comparison of Experimental and Simulated Stress Relaxation Data at Different Temperatures (a) $560^{\circ} \mathrm{C}$ (b) $580^{\circ} \mathrm{C}$. 
Fig. (6) shows the comparison of stress relaxation between experiment and simulation at different temperatures (a) $560^{\circ} \mathrm{C} \mathrm{(b)} 580^{\circ} \mathrm{C}$. It can be found from the figure that the predicted data obtained from the FEM show a good agreement with the measured results, which shows FEM can be used for modeling viscoelastic material behavior during lens molding and the obtained model parameters is feasibility. Meanwhile, The conclusion that the stress relaxing faster with higher temperature can be attained.

Fig. (7) shows the load variation at different time. For comparison, the experimental data and simulation data were compared in the figure. It is found that the trends of the results are basically the same, although there are some small deviations. Therefore, the proposed model that was used to express the deformation behavior of L-LAH84 glass is reasonable in this paper.

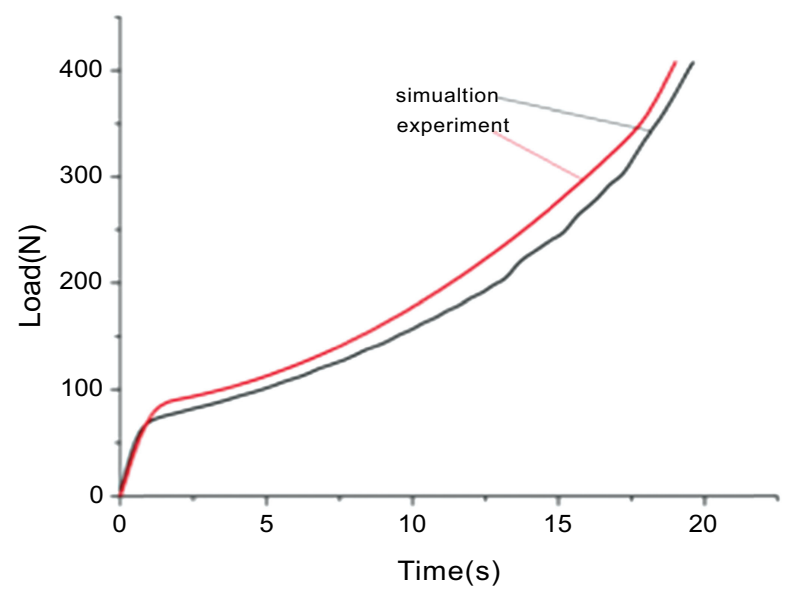

Fig. (7). Load variation data obtained by experiment and simulation at $560{ }^{\circ} \mathrm{C}$.

\subsection{Simulation of Lens Forming Stage}

Fig. (8) shows the two dimensional symmetric FEM model of lens molding. The glass sample was meshed into 2900 four-node elements. Without considering molds deformation, upper and lower molds were modeled as rigid bodies. Heat transfer at the glass-mold interface was neglected.

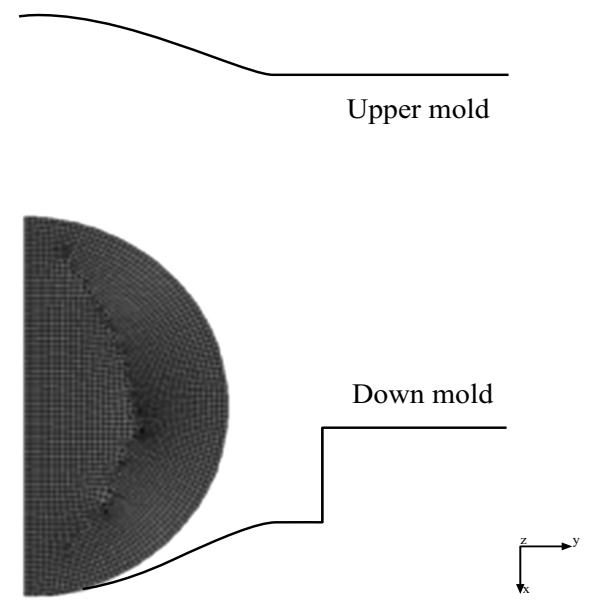

Fig. (8). FEM model of lens molding. (a)

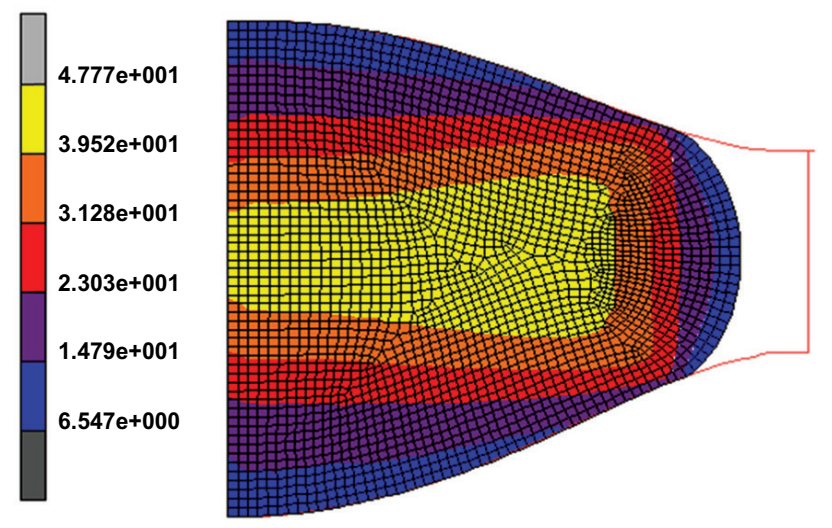

Equivalent Von Mises Stress (MPa)

(b)

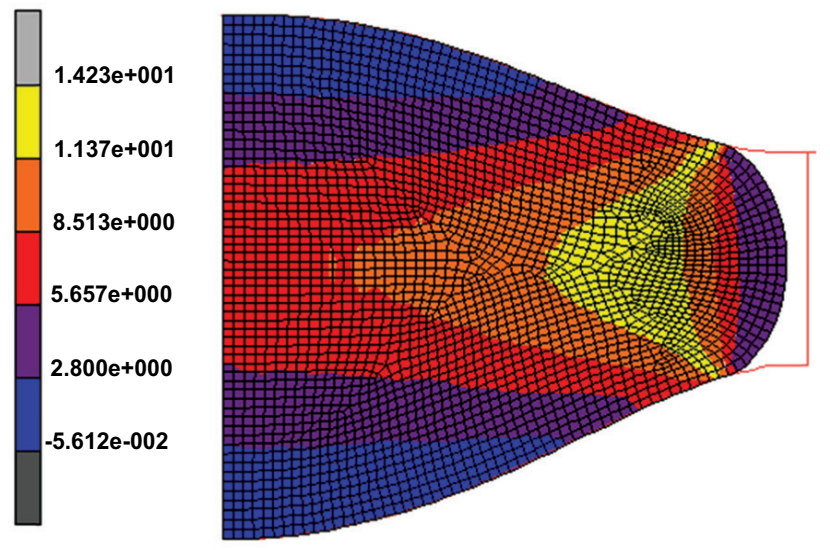

Equivalent Von Mises Stress (MPa)

(c)

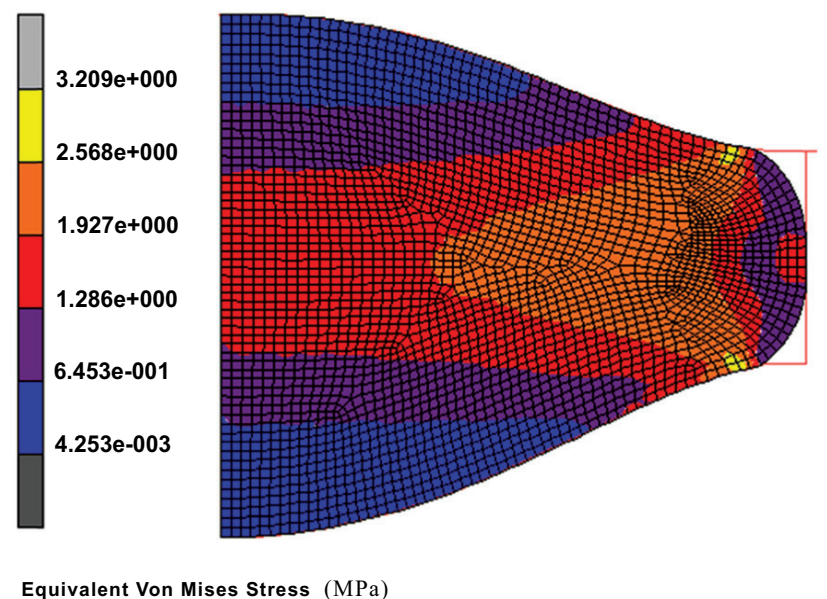

Fig. (9). Comparison of predicted stresses distribution at different molding temperatures (a) $560^{\circ} \mathrm{C} \mathrm{(b)} 580^{\circ} \mathrm{C}$ and (c) $600{ }^{\circ} \mathrm{C}$.

In order to analyze the influence of temperature on stress in lens. the molding speed is set to $1 \mathrm{~mm} / \mathrm{sec}$ constantly, while the temperatures are varied from $560{ }^{\circ} \mathrm{C}$ to $600{ }^{\circ} \mathrm{C}$. The stresses distribution predicted by FEM at three different molding temperatures are shown in Fig. (9). From the figure 
we can find that the maximum stress appear at the edge of lens. Higher stress will cause lens rupture easily at this zone, which was verified by experiment results, as shown in Fig. (10). Consider from another aspect, large stress inside lens will make glass refractive index change, which will affect imagining quality [9]. The other conclusion that with the temperature increasing the stresses inside the molded lens decreasing can be attained from Fig. (9). This phenomenon can be explained from two aspects. One is that glass viscosity continues to fall exponentially with temperature increasing, which makes flow ability of glass better and reduce the stress. The other reason is that stress relax faster at higher temperature, as explained above. From Fig. (9), another phenomenon that with the temperature increasing, the filling ratio is increasing can be found obviously.
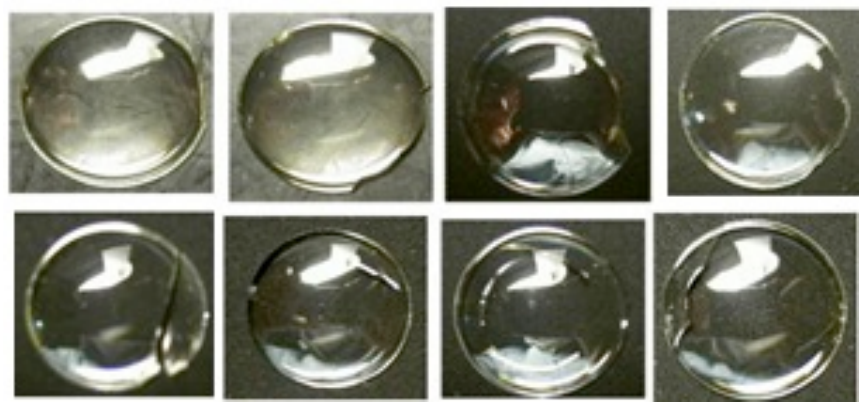

(a)
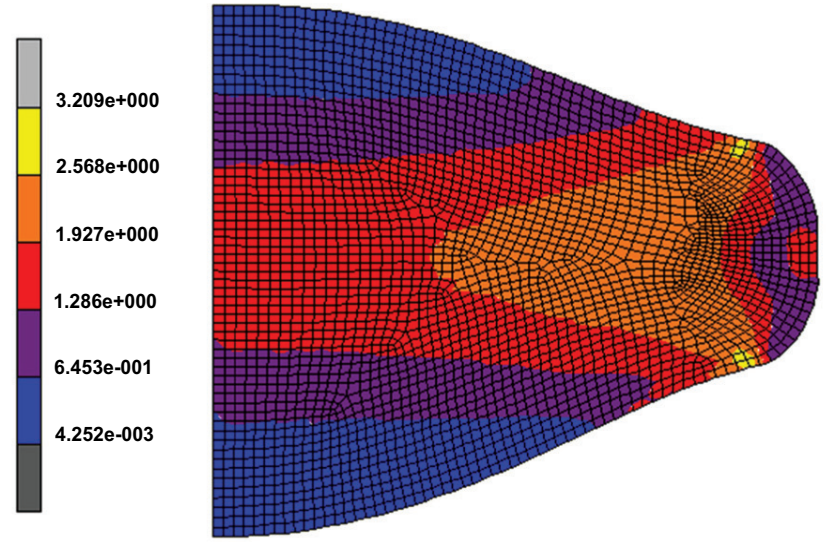

Equivalent Von Mises Stress (MPa)

(b)
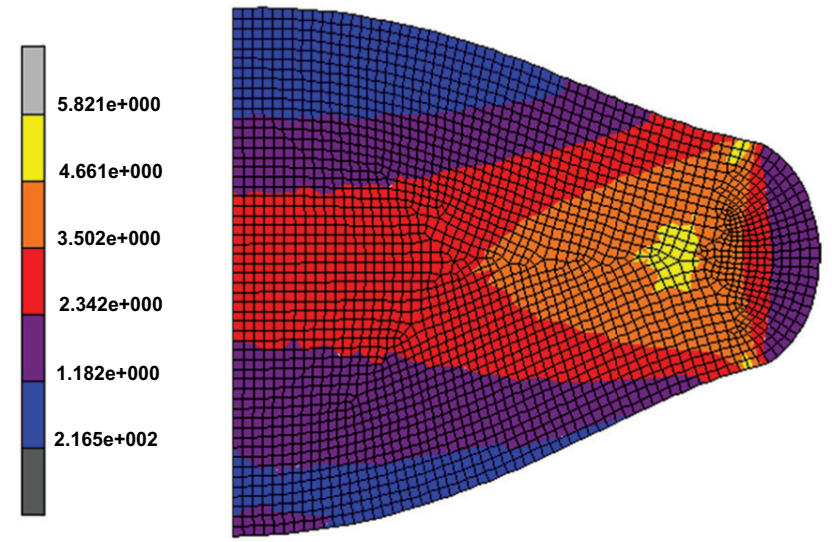

Equivalent Von Mises Stress (MPa)

(c)

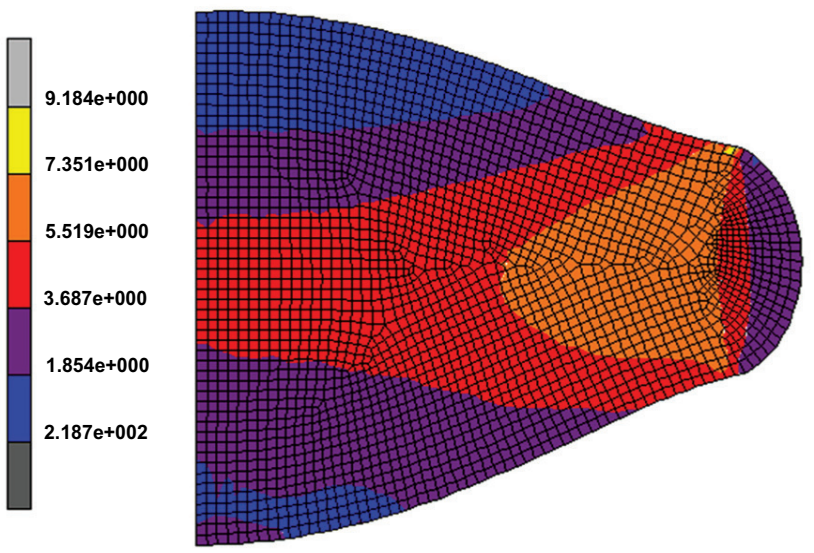

Equivalent Von Mises Stress (MPa)

Fig. (11). Comparison of Predicted Stresses Distribution at Different Molding velocities (a) $1 \mathrm{~mm} / \mathrm{sec}$ (b) $2 \mathrm{~mm} / \mathrm{sec}$ and (c) 3 $\mathrm{mm} / \mathrm{sec}$. 


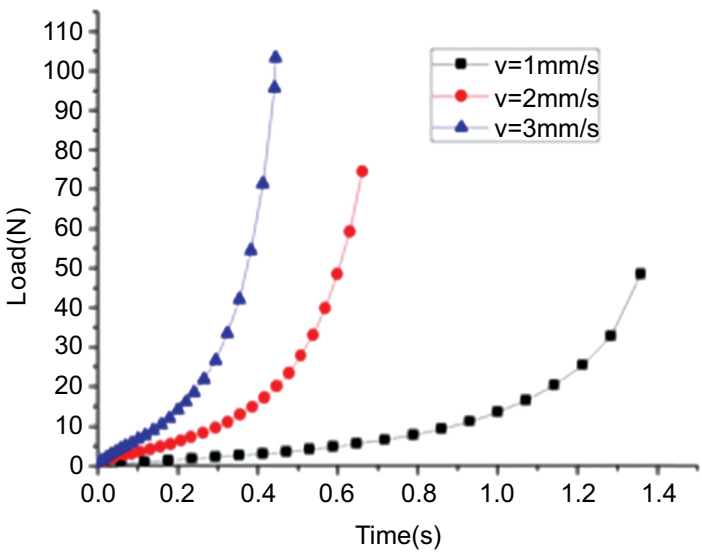

Fig. (12). Predicted load variation at different time for different velocities at $600^{\circ} \mathrm{C}$.

(2) Stress relaxation experiments were done by designed forming machine. A 4-pair Maxwell model parameters attained by fitting the experimental data can express viscoelastic well. Meanwhile, a reasonable agreement between the measured and predicted load during molding process was also obtained. These results show the 4-pair Maxwell model can be used in finite element analysis of the lens molding process.

(3) The forming stage of aspherical lens has been simulated by FEM under different process conditions. It was found that maximum stress is located at the edge of lens, which will make lens broken easily at this zone. Meanwhile, the simulation results show higher velocity mean higher stress and higher temperature mean lower stress.

\section{CONFLICT OF INTEREST}

The authors confirm that this article content has no conflict of interest.

\section{ACKNOWLEDGEMENTS}

Declared none.

\section{REFERENCES}

[1] Zhou TF, Yan J, Masuda J, Kuriyagawa T. Investigation on the viscoelasticity of optical glass in ultraprecision lens molding process. J Mater Proces Technol 2008; 209: 4484-9.

[2] Chang SH, Lee YM, Jung TS. Simulation of an aspheric glass lens Forming behavior in progressive GMP process. Proc $7^{\text {th }}$ Int Conf Numer Meth Indust Forming Proces, Portuga, 2007, pp. 1055-60.

[3] Masuda J, Yan J, Kuriyagawa T. Application of the NiP-plated steel molds to glass lens molding. Proc 10th Int Symp Adv Abrasive Technol, Sydney, 2007; pp. 123-30.

[4] Soules TF, Busbey RF, Berkhson SM, Markovsky A. Finite element calculation of stresses in glass parts undergoing viscous relaxation. J Am Ceram Soci 1987; 70: 90-5.

[5] Jain A, Yi AY. Numerical modeling of viscoelastic stress relaxation during glass lens forming process. J Am Ceram Soci 2005; 88: 530-5.

[6] Jain A, Firestone GC, Yi AY. Viscosity measurement by cylindrical compression for numerical modeling of precision lens molding process. J Am Ceram Soc 2005; 88: 2409-14.

[7] Jain A, Yi AY, Xie XP. Sooryakumar R. Finite element modelling of stress relaxation in glass moulding using measured, temperaturedependent elastic modulus and viscosity data of glass. Model Simul Mater Sci Eng 2006; 14: 465-77.

[8] Kobayashi H, Takahashi H, Hiki Y. Temperature dependence of the viscosity through the glass transition in metaphosphate glasses and polystyrene. Mater Sci Eng 2006; 442: 263-7.

[9] Su LJ, Chen Y, Yi AY, Klocke F, Pongs G. Refractive index variation in compression molding of precision glass optical components. Appl Opt 2008; 47: 1662-7.

(C) Xiaobing and Shaohui; Licensee Bentham Open.

This is an open access article licensed under the terms of the Creative Commons Attribution Non-Commercial License (http://creativecommons.org/licenses/ by-nc/3.0/) which permits unrestricted, non-commercial use, distribution and reproduction in any medium, provided the work is properly cited. 